\title{
Crescimento do morangueiro: influência da cultivar e da posição da planta no canteiro
}

\author{
Strawberry growth: effect of cultivar and plant position in the bed
}

\author{
André Samuel Strassburger ${ }^{\mathrm{I}, \mathrm{II}^{*}}$ Roberta Marins Nogueira Peil ${ }^{\mathrm{I}}$ José Ernani Schwengber $^{\mathrm{II}}$ \\ Denise de Souza Martins ${ }^{\mathrm{I}}$ Carlos Alberto Barbosa Medeiros ${ }^{\mathrm{II}}$
}

\section{- NOTA -}

\section{RESUMO}

\begin{abstract}
O objetivo deste trabalho foi avaliar o crescimento de cultivares de morangueiro em sistema de cultivo orgânico, observando a influência da posição da planta no canteiro sobre a produção acumulada e a partição de massa seca entre os órgãos aéreos das plantas. O experimento foi realizado na Embrapa Clima Temperado, Estação Experimental Cascata, Pelotas, RS. Os tratamentos constaram da combinação de dois fatores experimentais: cultivar ('Albion', 'Aromas', 'Camarosa' e 'Camino Real') e a posição das plantas no canteiro (Central e Bordadura). O delineamento experimental adotado foi o de blocos completos casualizados com parcelas divididas e quatro repetições. A cultivar 'Camarosa' apresentou maior produção de massa seca dos órgãos aéreos das plantas $\left(62,3 ; 27,5\right.$ e 88,0g planta ${ }^{-1}$ para folha, coroa e frutos, respectivamente) $e$, juntamente com a 'Aromas', maior produtividade $\left(64,2\right.$ e 59,1 $\mathrm{Mg} \mathrm{ha}^{-1}$, respectivamente). A cultivar 'Aromas' apresentou a maior contribuição proporcional dos frutos para a composição do total de massa seca da planta $(60,6 \%)$ e o maior índice de colheita (88\%). A posição das plantas não influenciou o crescimento e a produtividade, indicando ausência de efeito de bordadura para as cultivares 'Albion', 'Aromas', 'Camarosa' e 'Camino Real'.
\end{abstract}

Palavras-chave: Fragaria $x$ ananassa Duch., sistema de cultivo orgânico, produção e partição de massa seca, efeito de bordo.

\section{ABSTRACT}

The aim of this research was to evaluate the growth of strawberry cultivars growing in organic crop system observing the influence of plant position in the bed on accumulated dry matter production and its partitioning among the aboveground plant organs. The experiment was conducted in Embrapa Clima Temperado, Estação Experimental Cascata, Pelotas, RS. The treatments were compose by the combination of two experimental factors: cultivar ('Aromas', 'Albion', 'Camarosa' and 'Camino Real') and plant position in the bed (Central and Border). The experimental design used was randomized blocks with split-plots and four replications. 'Camarosa' cultivar presented highest dry mass production of aboveground organs (62.3; 27.5 and 88.0g plant ${ }^{-1}$ for leaves, crown and fruits, respectively), and together 'Aromas', highest yield (64.2 and $59.1 \mathrm{Mg} \mathrm{ha} \mathrm{I}^{-1}$, respectively). 'Aromas' cultivar presented highest fruit dry mass contribution for the total aboveground dry mass production (60.6\%) and the highest harvest index (88\%). The plant position in the bed did not influence the growth and yield of the plants, which indicate no border effect for the 'Albion', 'Aromas', 'Camarosa' and 'Camino Real' strawberry cultivars.

Key words: Fragaria x ananassa Duch., organic crop system, dry mass production and partitioning, border effect.

Um dos fatores determinantes para o sucesso de uma lavoura de morangueiro é a escolha da cultivar a ser utilizada. A duração do ciclo, a produtividade, a qualidade da fruta, a resistência contra as principais pragas e doenças e a distribuição da produção durante o ciclo de cultivo são aspectos fundamentais a serem considerados no momento da escolha da cultivar (GIMENEZ, 2007). Em se tratando de sistemas de cultivo orgânico do morangueiro, um aspecto adicional a ser considerado é que os programas

'Departamento de Fitotecnia, Faculdade de Agronomia Eliseu Maciel (FAEM), Universidade Federal de Pelotas (UFPEL), Campus Universitário s/n, CP 354, 96010-900, Pelotas, RS, Brasil. E-mail: strassburger.as@ gmail.com. *Autor para correspondência.

"Empresa Brasileira de Pesquisa Agropecuária, Centro de Pesquisa Agropecuária de Clima Temperado, Estação Experimental Cascata, Pelotas, RS, Brasil. 
de melhoramento genético, nas quais as cultivares modernas foram desenvolvidas, caracterizam-se pela avaliação e seleção de clones em sistema de cultivo convencional. Dessa forma, as cultivares provenientes desses programas podem apresentar menor crescimento, produtividade e menor qualidade da produção em sistemas de cultivo orgânico (CASTRO et al., 2003).

Em uma parcela experimental, é frequente a ocorrência de diferenças entre o desempenho de plantas das fileiras da bordadura e o desempenho de plantas da parte central do canteiro. As linhas de bordadura das unidades experimentais geralmente não são aproveitadas para a obtenção dos dados experimentais, sendo uma técnica experimental utilizada para reduzir o efeito da competição interparcelar (STORCK et al., 2000). Em experimentos realizados com o morangueiro, o efeito de bordadura torna-se ainda mais importante, pois geralmente são empregadas três ou quatro linhas de plantas por canteiro. Dependendo dos objetivos da pesquisa e das variáveis avaliadas, a utilização de bordadura aumenta significativamente o tamanho da parcela, o que dificulta a condução do experimento em virtude dos numerosos tratos culturais exigidos por essa cultura.

Dessa forma, o objetivo deste trabalho foi avaliar o crescimento de cultivares de morangueiro em sistema de cultivo orgânico, observando a influência da posição da planta no canteiro sobre a produção acumulada e a partição de massa seca entre os órgãos aéreos das plantas.

Oexperimento foi realizado na Embrapa Clima Temperado, Estação Experimental Cascata, localizada no município de Pelotas, RS. A localização geográfica aproximada é $31^{\circ} 37^{\prime} \mathrm{S}, 52^{\circ} 31^{\prime} \mathrm{W}$ e altitude de $181 \mathrm{~m}$. O clima é do tipo Cfa (MOTA et al., 1975) e o solo da área experimental é classificado como Argissolo vermelhoamarelo eutrófico.

Foram utilizados quatro canteiros com dimensões de $1,1 \times 15,0 \times 0,3$ e caminhos de $0,5 \mathrm{~m}$, abrigados por túneis baixos, cobertos com filme de polietileno de baixa densidade (PEBD) transparentes com $100 \mu \mathrm{m}$ de espessura, dispostos no sentido LesteOeste. A correção do solo foi realizada conforme o resultado da análise química do solo (TEDESCO et al., 1995), levando-se em consideração as recomendações da SBCS/NRS (2004) para a cultura do morangueiro. Para a correção do $\mathrm{pH}$, foram aplicados $2,7 \mathrm{Mg} \mathrm{ha}^{-1} \mathrm{de}$ calcário dolomítico, com um PRNT de 98\%. Para a correção da fertilidade do solo foram utilizados $18,6 \mathrm{Mg}$ ha $^{-1}$ de vermicomposto bovino e $24,0 \mathrm{Mg} \mathrm{ha}^{-1}$ de torta de mamona, tendo-se como base para a aplicação o teor de potássio.
As mudas eram provenientes de viveiro chileno e foram transplantadas no dia 12/05/2008. $\mathrm{O}$ espaçamento utilizado foi de $0,3 \times 0,3 \mathrm{~m}$, com três fileiras por canteiro, dispostas em sistema de quincôncio, totalizando uma densidade de 5,26 plantas $\mathrm{m}^{-2}$ (considerando a área total de cultivo, incluindo os caminhos). A irrigação das plantas foi realizada por gotejamento, utilizando-se húmus líquido para a fertirrigação com a seguinte composição química: de $173,7 \mathrm{mg} \mathrm{L}^{-1}$ de N; 22,5mg L-1 de P; 536,6mg L $\mathrm{me} \mathrm{K}^{-1}$; $29,4 \mathrm{mg} \mathrm{L}^{-1} \mathrm{de} \mathrm{Ca} ; 635,7 \mathrm{mg} \mathrm{L}^{-1} \mathrm{de} \mathrm{Mg} ; 31,5 \mathrm{mg} \mathrm{L}^{-1} \mathrm{deNa}$; $\mathrm{pH}$ de 6,9 e condutividade elétrica de $2,31 \mathrm{mS} \mathrm{cm}^{-1}$. A cobertura dos canteiros foi realizada com plástico preto (PEBD), com $50 \mu \mathrm{m}$ de espessura. O controle de pragas e de doenças foi realizado utilizando-se calda bordalesa, calda sulfocálcia, óleo de Nim e alhol.

Os tratamentos experimentais constaram da combinação de dois fatores: cultivar ('Albion', 'Aromas', 'Camarosa' e 'Camino Real') e posição da planta no canteiro (Central e Bordadura). O delineamento experimental adotado foi o de blocos completos casualizados, com quatro repetições e parcelas divididas, sendo que o fator cultivar constituiu a parcela e o fator posição da planta a subparcela. Posteriormente ao transplante, foram selecionadas duas plantas por repetição, sendo uma na fileira central da parcela e outra em uma das fileiras de bordadura, sobre as quais se manteve total controle da colheita, da remoção de folhas e de estolões durante o período de cultivo. O crescimento da cultura foi determinado por meio da quantificação da produção e partição da massa seca aérea acumulada das plantas controle aos 241 dias após o transplante (07/01/2009). Os resultados foram submetidos à análise de variância e as médias comparadas pelo teste DMS de Fisher $(\mathrm{P}>0,05)$.

A produção de massa seca das folhas e da coroa (Tabela 1) foi superior na cultivar 'Camarosa' em comparação às demais, o que elevou a produção de massa seca do compartimento vegetativo nessa cultivar. As cultivares 'Albion', 'Aromas' e 'Camino Real' apresentaram valores semelhantes para essas variáveis. A 'Camarosa' também apresentou maior produção de massa seca dos frutos, seguida, respectivamente, pelas cultivares 'Aromas', 'Albion' e 'Camino Real', todas diferindo estatisticamente entre si.

A cultivar 'Aromas' apresentou maior contribuição proporcional dos frutos em detrimento da fração vegetativa para a composição do total de massa seca aérea (Tabela 1), o que elevou seu índice de colheita (IC), o qual alcançou valor de $88 \%$, valor este estatisticamente superior ao das demais cultivares, que apresentaram média geral de $81 \%$. Observa-se ainda que, em todas as cultivares, a massa seca dos 
Tabela 1 - Produção acumulada e partição de massa seca de plantas de morangueiro em sistema de cultivo orgânico, de acordo com a cultivar e a posição da planta no canteiro. Embrapa Clima Temperado, Pelotas, 2009.

\begin{tabular}{|c|c|c|c|c|c|c|c|}
\hline \multirow{2}{*}{ Cultivar } & \multicolumn{3}{|c|}{------Produção de massa seca $\left(\mathrm{g}_{\text {planta }}{ }^{-1}\right)$------ } & \multicolumn{3}{|c|}{------Partição de massa seca (\%)-------- } & \multirow{2}{*}{$\begin{array}{l}\text { Produtividade } \\
\left(\mathrm{Mg} \mathrm{ha}^{-1}\right)\end{array}$} \\
\hline & Folhas & Coroa $^{1}$ & $\mathrm{FV}^{2}$ & Frutas & Frutas/Planta ${ }^{3}$ & FV/Planta & \\
\hline 'Albion' & $35,6 b^{5}$ & $16,7 \mathrm{~b}$ & $52,3 \mathrm{~b}$ & $58,2 \mathrm{c}$ & $52,7 \mathrm{~b}$ & 47,3 a & $37,3 b^{5}$ \\
\hline 'Aromas' & $32,6 \mathrm{~b}$ & $15,0 \mathrm{~b}$ & $47,6 \mathrm{~b}$ & $73,1 \mathrm{~b}$ & $60,6 \mathrm{a}$ & $39,4 \mathrm{~b}$ & $59,1 \mathrm{a}$ \\
\hline 'Camarosa' & 62,3 a & $27,5 \mathrm{a}$ & 89,8 a & 88,0 a & $49,5 \mathrm{~b}$ & $50,5 \mathrm{a}$ & $64,2 \mathrm{a}$ \\
\hline 'Camino Real' & $32,1 \mathrm{~b}$ & $15,0 \mathrm{~b}$ & $47,1 \mathrm{~b}$ & $47,8 \mathrm{~d}$ & $50,4 \mathrm{~b}$ & 49,6 a & $36,6 \mathrm{~b}$ \\
\hline \multicolumn{8}{|c|}{ Posição da Planta ${ }^{4}$} \\
\hline Central & $41,2 \mathrm{a}^{6}$ & 18,6 a & 59,8 a & $68,4 \mathrm{a}$ & 53,4 a & 46,6 a & 49,5 a \\
\hline Bordadura & $40,1 \mathrm{a}$ & 18,5 a & 58,6 a & $65,1 \mathrm{a}$ & 52,6 a & $47,4 \mathrm{a}$ & $49,1 \mathrm{a}$ \\
\hline $\mathrm{CV}(\%)$ & 25,5 & 24,4 & 22,8 & 11,4 & 11,5 & 13,3 & 14,2 \\
\hline
\end{tabular}

1. Coroa corresponde à soma da coroa + estolões + pedúnculos; ${ }^{2}$ FV (Fração vegetativa) corresponde à soma: folhas + coroa; ${ }^{3 .}$ Planta corresponde à soma fração vegetativa + frutas; ${ }^{4}$. Determinada pela localização da planta no canteiro em relação ao caminho; ${ }^{5}$. Médias seguidas da mesma letra para o fator cultivar não diferem entre si pelo teste DMS de Fisher (P>0,05); ${ }^{6 .}$ Médias seguidas da mesma letra para o fator posição da planta não diferem entre si pelo teste $\mathrm{F}(\mathrm{P}>0,05)$.

frutos representou a maior fração proporcional da massa seca total das plantas, em comparação aos demais órgãos avaliados (folhas e coroa). A partição de massa seca entre as folhas e a coroa no compartimento vegetativo apresentou padrão semelhante para as cultivares estudadas, sendo que as folhas representaram $68,6 \%$ e a coroa $31,4 \%$ da massa seca desse compartimento.

Na cultivar 'Camarosa', o crescimento foliar foi superior em comparação às demais, evidenciado pelo maior índice de área foliar (IAF; $3,5 \mathrm{~m}^{2} \mathrm{~m}^{-2}$ ), valor superior aos observados nas demais cultivares, que não diferiram entre si e apresentaram média geral de $1,5 \mathrm{~m}^{2} \mathrm{~m}^{-2}$. O IAF indica o tamanho do aparelho assimilatório da planta e reflete sua capacidade produtiva (HUNT, 1981). Assim, a maior produção de massa seca da 'Camarosa' pode ser associada à maior capacidade de expansão do aparato fotossintético, o que proporcionou maior interceptação da radiação solar e maior produção de fotoassimilados.

Embora a produção de massa seca dos frutos tenha sido superior na 'Camarosa', o maior teor de água nos frutos da 'Aromas' proporcionou que a produtividade entre essas duas cultivares não diferisse. Para a 'Camarosa', o teor de massa seca dos frutos foi de 7,2\%, estatisticamente superior ao encontrado na 'Aromas' (6,2\%), que apresentou o menor valor dentre as cultivares estudadas. A 'Albion' apresentou maior teor de massa seca dos frutos $(8,2 \%)$, valor significativamente superior ao de todas as cultivares, enquanto que a 'Camino Real' apresentou valor semelhante ao da 'Camarosa' (6,9\%).

Os resultados obtidos em relação à produtividade variaram de $36,6 \mathrm{Mg} \mathrm{ha}^{-1}\left(696 \mathrm{~g}\right.$ planta $\left.^{-1}\right)$, na 'Camino Real' e na 'Albion', a 64,2Mg ha-1 $(1220 \mathrm{~g}$ planta $\left.^{-1}\right)$, na 'Camarosa', sendo semelhantes aos obtidos por FERNANDES JÚNIOR et al. (2002), CASTRO et al. (2003), ANDRIOLO et al. (2009), indicando que o sistema de cultivo orgânico pode apresentar produtividades compatíveis às obtidas em outros sistemas de produção.

Em relação à posição das plantas no canteiro, observou-se uma semelhança expressiva para as variáveis relacionadas ao crescimento das plantas (Tabela 1) e à produtividade da cultura. Considera-se que, em plantas sadias e adequadamente supridas de água e nutrientes, a fotossíntese líquida e a produção de fotoassimilados sejam proporcionais à quantidade de radiação fotossinteticamente ativa disponível para as plantas (MONTEITH, 1972). Portanto, para a maioria das culturas, espera-se que a radiação solar disponível para as plantas de bordadura seja mais elevada em comparação com as plantas centrais, em virtude do menor sombreamento mútuo entre plantas, o que levaria a um maior crescimento e produtividade. Deve-se considerar, porém, que, devido à arquitetura da planta de morangueiro, de porte baixo e com a disposição das folhas concentradas ao redor da coroa, o sombreamento mútuo entre as plantas não é tão contundente quanto o observado em espécies de maior porte, como as solanáceas e as cucurbitáceas. Dessa forma, a radiação solar disponível não foi limitante a ponto de interferir no crescimento das plantas do centro do canteiro. Assim, a produção e a partição de massa seca, a produtividade, o IC (média de $83 \%$ ) e o IAF (média de $2 \mathrm{~m}^{2} \mathrm{~m}^{-2}$ ) também não foram influenciados pela posição das plantas no canteiro. 
De acordo com os resultados obtidos, pode-se concluir que a cultivar de morangueiro 'Camarosa' apresenta maior produção de massa seca dos órgãos aéreos das plantas e, juntamente com a 'Aromas', maior produtividade. Além disso, a posição das plantas no canteiro não influencia o crescimento e a produtividade das plantas de morangueiro das cultivares 'Albion', 'Aromas', 'Camarosa' e 'Camino Real'.

\section{REFERÊNCIAS}

ANDRIOLO, J.L. et al. Concentração da solução nutritiva no crescimento, na produtividade e na qualidade de frutas do morangueiro. Ciência Rural, Santa Maria, v.39, nº 3, p.684-690, 2009. Disponível em: <http://www.scielo.br/scielo.php?script=sci_abstract\&pid=S0103$84782009000300009 \& \operatorname{lng}=\mathrm{pt} \& \mathrm{nrm}=\mathrm{iso} \& \operatorname{tn} \mathrm{n}=\mathrm{pt}>$. Acesso em: 26jun. 2009. doi: 10.1590/S0103-84782009005000008.

CASTRO, R.L. et al. Produtividade de cultivares de morangueiro em sistema de cultivo orgânico. Horticultura Brasileira, Brasilia, v.21, n.2, p.227-230, 2003. Disponível em: <http:// www.scielo.br/scielo.php? script=sci_abstract $\&$ pid $=$ S0102$05362003000200021 \& \operatorname{lng}=p t \& n r m=i s o \& t \operatorname{lng}=p t>$. Acesso em: 12 dez. 2007. doi: 10.1590/S0102-05362003000200021.

FERNANDES JÚNIOR, F. et al. Produção de frutos e estolhos de morangueiro em diferentes sistemas de cultivo em ambiente protegido. Bragantia, Campinas, v.61, n.1, p.25-34, 2002. Disponível em:
<http://www.scielo.br/scielo.php?script=sci_abstract\&pid=S0006$87052002000100005 \& \operatorname{lng}=\mathrm{pt} \& \mathrm{nrm}=\mathrm{iso} \& \mathrm{t} \operatorname{lng} \mathrm{g}=\mathrm{pt}>$. Acesso em: 08 jul. 2005. doi: 10.1590/S0006-87052002000100005.

GIMENEZ, G. Desenvolvimento de novas cultivares de morangueiro. In: ANDRIOLO, J.L. Seminário sobre o cultivo hidropônico do morangueiro. Santa Maria, UFSM, 2007. p.3-8.

HUNT, R. Growth analysis of populations and communities. In: HUNT, R. Plant growth analysis. London: Edward Arnold, 1981. Cap.4, p.26-38.

MONTEITH, J.L. Solar radiation and productivity in tropical ecosystems. Journal of Applied Ecology, v.9, p.747-766, 1972.

MOTA, F.S. et al. Estação agroclimatológica de Pelotas: realizações e programa de trabalho. Pelotas: Universidade Federal de Pelotas, 1975. 72p.

SBCS/NRS. Manual de adubação e calagem para os Estados do Rio Grande do Sul e de Santa Catarina. 10.ed. Porto Alegre: Comissão de Química e Fertilidade do Solo - RS/SC. Sociedade Brasileira de Ciência do Solo/Núcleo Regional Sul, 2004. 396p.

STORCK, L. et al. Experimentação vegetal. Santa Maria: UFSM, 2000. 198p.

TEDESCO, M.J. et al. Análises de solo, plantas e outros materiais. 2.ed. Porto Alegre: Universidade Federal do Rio Grande do Sul, 1995. 174p. 